Munro, D. S. (1971). In Current Topics in Experimental Endocrinology, ed. L. Martini and V. H. T. James, vol. 1, p. 175. New York, Academic

Shishiba, Y., Shimizu, T., Yoshimura, S., and Shizume, K. (1973). fournal of Clinical Endocrinology and Metabolism, 36, 517.
Solomon, D. H., and Chopra, I. J. (1972). Mayo Clinic Proceedings, 47, 803. Volpé, R., Edmonds, M., Lamki, L., Clark, P. V., and Row, V. V. (1972). Mayo Clinic Proceedings, 47, 824.

Werner, S. C., Wegelius, O., Fierer, J. A., and Hsu, K. C. (1972). New England fournal of Medicine, 287, 421.

\title{
Pharmacological Studies with Lincomycin in Late Pregnancy
}

\author{
N. M. DUIGNAN, J. ANDREWS, J. D. WILLIAMS
}

British Medical fournal, 1973, 3, 75-78

\section{Summary}

The placental transmission of lincomycin was studied in 60 patients in late pregnancy. A peak maternal blood level of $12.5 \mu \mathrm{g} / \mathrm{ml}$ was recorded 45 minutes after injection, and detectable levels were still present up to 42 hours after a single injection. A peak cord blood level of $2.7 \mu \mathrm{g} / \mathrm{ml}$ was recorded 55 minutes after injection; cord blood levels were about a quarter of the maternal blood levels, and in most cases no levels were detectable 24 hours after a single injection. The passage of lincomycin into and out of the liquor was slower and more variable, but some hours after injection the liquor levels were always higher than the maternal or cord blood levels, and detectable levels were still present in the liquor 52 hours after a single injection. Repeated injections did not lead to any significant accumulation of lincomycin. The only side effect was a possible case of neuromuscular block in a mother delivered by caesarean section. No infant was adversely affected.

\section{Introduction}

Improved aseptic techniques and the active management of labour, as advocated by O'Driscoll et al. (1969, 1970), have helped almost to eliminate the problem of intrauterine infection during labour. Occasional cases still occur, especially after premature rupture of the membranes. More commonly intrauterine infection occurs after septic abortion in early pregnancy. In the three years $1967-9,88$ maternal deaths occurred in England and Wales from sepsis, 12 after delivery, 62 after abortion, and 14 after surgical intervention in pregnancy (D.H.S.S., 1972).

The organisms usually isolated in cases of intrauterine infection are streptococci or bacteroides. Gram-negative organisms may also be commonly isolated but their pathological role is not clear, while infection with Clostridium welchii or staphylococcus pyogenes may also occur, but less frequently. Bacteroides species vary greatly in their sensitivity to antibiotics, and a combination of penicillin and chloromycetin has commonly been used to treat obstetric cases (Pearson and Anderson, 1967, 1970). Recently lincomycin has been shown to be very effective

Dudley Road Hospital, Birmingham B18 7QH

N. M. DUIGNAN, M.A.o., M.R.C.o.G., Senior Registrar, Department of Obstetrics and Gynaecology.

J. ANDREWS, F.I.M.L.T., Chief Technician, Department of Microbiology J. D. WILLIAMS, M.D., M.R.C.PATH., Consultant Microbiologist in the treatment of bacteroides infection (Geddes et al., 1967; Tracy et al., 1972). In addition to its activity against bacteroides, lincomycin is also very active against Gram-positive organismsnotably, staphylococci, haemolytic streptococci, and pneumococci. It is not active against Gram-negative bacilli or gonococci.

Gray et al. (1964) found that lincomycin crossed the placental barrier in rats without causing side effects, and Medina et al. (1964) recorded levels of $1.5-6.9 \mu \mathrm{g} / \mathrm{ml}$ in cord blood and liquor two to four hours after an intramuscular injection of $600 \mathrm{mg}$. However, despite its potential value in the treatment of intrauterine infection, there have been no detailed studies of the placental transfer of lincomycin. The present investigation was undertaken in order to determine whether lincomycin crossed the placental barrier in concentrations sufficient to justify its use in the treatment of intrauterine infection with bacteroides or Grampositive cocci. Lincomycin was studied in preference to clindamycin because it can be given intramuscularly and is therefore more suitable for use during labour.

\section{Patients and Methods}

Clinical Procedures.-Sixty patients who were admitted to hospital for caesarean section, admitted for induction of labour because of postmaturity, or admitted in early labour with intact membranes were studied. They were divided into three groups: (1) 32 patients were each given lincomycin $600 \mathrm{mg}$ by intramuscular injection at selected times from 20 minutes to 12 hours before artificial rupture of the membranes (A.R.M.). Lincomycin $600 \mathrm{mg}$ was continued at 12-hourly intervals until delivery, but because of the active management of labour only seven patients received two doses and none received more than two. (2) 22 patients were given one intramuscular dose of lincomycin $600 \mathrm{mg}$ at selected times between 12 and 52 hours before A.R.M. They were not given lincomycin during labour. (3) Five patients received two, and one patient received four, 12-hourly doses of lincomycin $600 \mathrm{mg}$ before A.R.M. was performed. None of these patients received lincomycin after A.R.M. Liquor was collected at the time of A.R.M. by rupturing the hind-waters with a Drew-Smythe catheter; the forewaters were also ruptured after collection of the sample. Maternal blood was collected at the time of A.R.M. and at delivery. Cord blood was collected at delivery. The administration of the drug was part of a research procedure, and full consent of the patients was given.

Laboratory Methods.-Antibiotic levels were determined by the cup plate method using Sarcina lutea as test organisms incorporated into Difco antibiotic medium 11. Standard solutions of antibiotic were prepared in a diluent appropriate to the material under assay. All specimens were stored at $-20^{\circ} \mathrm{C}$ until assay, which was performed within 72 hours of collection. 
TABLE I-Maternal Blood, Cord Blood, and Liquor Levels of Lincomycin in $\mu \mathrm{g} / \mathrm{ml}$ after one Intramuscular Injection of 600 mg

\begin{tabular}{|c|c|c|c|c|c|c|c|c|c|}
\hline Hour & rs after & Injection: & $\leqslant 2$ & -4 & -8 & -12 & -24 & -36 & -52 \\
\hline $\begin{array}{l}\text { Maternal blood: } \\
\text { No. of specimens } \\
\text { Range } \\
\text { Mean } \pm \text { S. } \\
\text { Cord blood: } \\
\text { No. of specimens } \\
\text { Range } \\
\text { Mean } \pm \text { S. } \ddot{D} . \\
\text { Liquor: } \\
\text { No. of specimens } \\
\text { Range } \pm \text { S. } . \\
\text { Mean. }\end{array}$ & $\begin{array}{l}\ldots \\
\cdots \\
\cdots \\
\cdots \\
\cdots \\
\cdots \\
\cdots\end{array}$ & 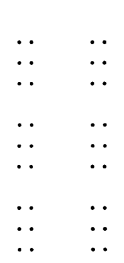 & $\begin{array}{c}3.5 \frac{10}{12.5} \\
8 \cdot 22 \pm 3 \cdot 15 \\
0.3 \frac{5}{-2.7} \\
2 \cdot 10 \pm 1.01 \\
10 \\
0 \frac{10}{1} 3.8 \\
1.18 \pm 1.35\end{array}$ & $\begin{array}{c}3.2 \frac{10}{-10.0} \\
6.51 \pm 2.03 \\
1.2 \frac{4}{4} 2.4 \\
1.62 \pm 0.54 \\
0.3-1.6 \\
0.7 \pm 0.44\end{array}$ & $\begin{array}{l}1.0 \frac{15}{-5.6} \\
3.31 \pm 1.39 \\
0.64 \frac{6}{-2.4} \\
1.27 \pm 0.73 \\
0.26 \frac{10}{1.50} \pm 0.95\end{array}$ & $\begin{array}{l}0.52 \frac{16}{-4.2} \\
2.01 \pm 1.16 \\
0.36 \frac{8}{-1.4} \\
0.87 \pm 0.40 \\
0.68 \frac{7}{1.1} \\
1.51 \pm 0.75\end{array}$ & $\begin{array}{l}0.16-23 \\
1.12 \pm 0.74 \\
0.17 \frac{9}{-} 0.52 \\
0.35 \pm 0.12 \\
0.98 \frac{14}{-} 3.5 \\
2.04 \pm 0.69\end{array}$ & $\begin{array}{c}0 \frac{12}{0} 0.8 \\
0.29 \pm 0.21 \\
0 \frac{10}{-0.5} \\
0.06 \pm 0.16 \\
1.3 \\
1.3\end{array}$ & $\begin{array}{c}0 \frac{7}{0} 0.31 \\
0.04 \pm 0.14 \\
6 \\
0.1 \\
0.16 \frac{5}{0.36} 0.6 \\
0.16\end{array}$ \\
\hline
\end{tabular}

\section{Results}

\section{SINGLE DOSE}

The range and mean levels of lincomycin obtained in maternal blood, cord blood, and liquor at varying times after one dose of lincomycin are summarized in table I.

A peak maternal blood level of $12.5 \mu \mathrm{g}$ lincomycin per ml was recorded within 45 minutes of injection. In all cases the blood levels fell gradually in a linear manner (fig. 1). A mean blood level of $3 \mu \mathrm{g} / \mathrm{ml}$ was still present eight hours after injection; all samples taken more than 42 hours after injection contained less then $0.1 \mu \mathrm{g} / \mathrm{ml}$.

A peak level of $2 \cdot 7 \mu \mathrm{g}$ lincomycin per $\mathrm{ml}$ was found in cord blood 55 minutes after injection. Cord blood levels of lincomycin were generally about a quarter of the maternal blood levels and also showed a linear regression (fig. 1). Only two of the 16 samples taken more than 24 hours after injection contained detectable levels of lincomycin and all samples taken more than 32 hours after injection contained less than $0.1 \mu \mathrm{g} / \mathrm{ml}$.

The levels of lincomycin obtained in the liquor are shown in fig. 2. The passage of lincomycin into and out of the liquor was

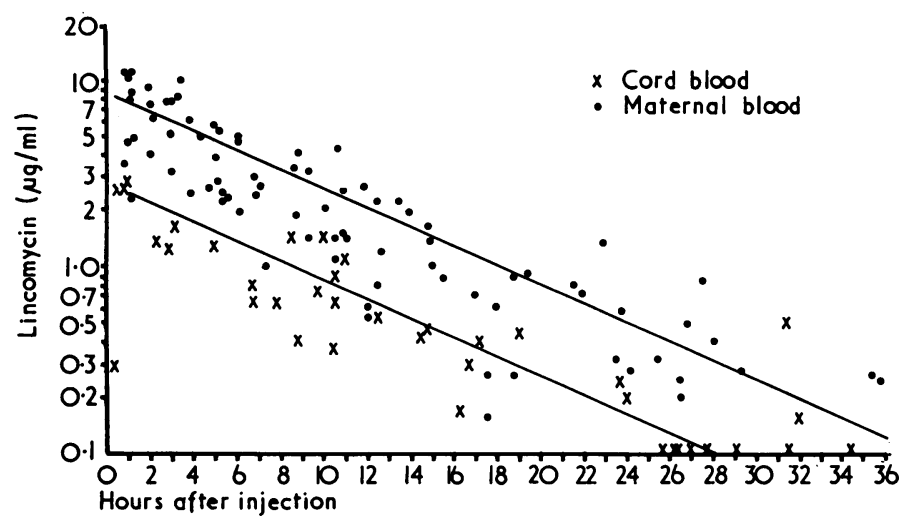

FIG. 1-Maternal and cord blood levels of lincomycin after one intramuscular injection of $600 \mathrm{mg}$.

slower and more variable than its entry into either the maternal or the cord blood. Levels rose somewhat erratically during the first 12 hours, after which time they remained fairly constant until they began to drop in linear manner 22 hours after injection. Detectable levels of lincomycin were still present 52 hours after a single injection. All liquor levels were greater than the maternal blood levels 16 hours after injection.

\section{CAESAREAN SECTION AND TWIN PREGNANCIES}

Seven patients undergoing caesarean section and three patients with twins were studied. This includes one patient with twins delivered by caesarean section. Samples of maternal blood, cord blood, and liquor were collected at the same time in sectioned patients and the results are shown in table II. The cord blood level of lincomycin was lower than the liquor level in case 15

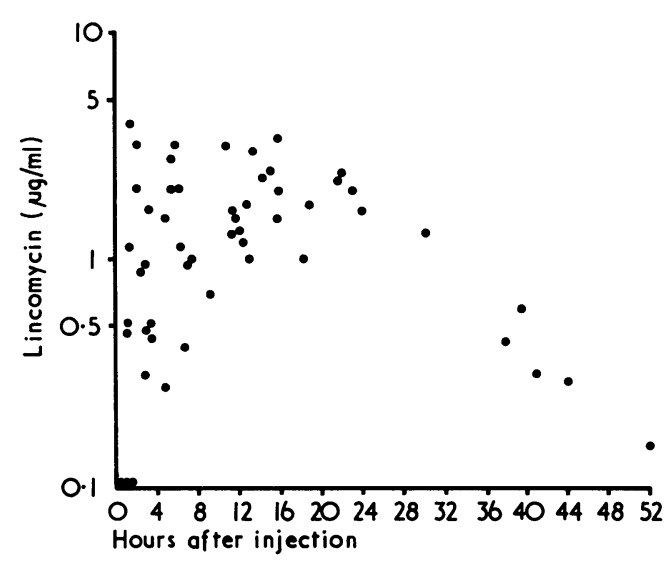

FIG. 2-Liquor levels of lincomycin after one intramuscular injection of $600 \mathrm{mg}$.

TABLE II-Maternal Blood, Cord Blood, and Liquor Levels of Lincomycin in $\mu \mathrm{g} / \mathrm{ml}$ obtained at Caesarean Section

\begin{tabular}{c|c|c|c|c}
\hline Case No. & $\begin{array}{c}\text { Time after } \\
\text { Injection }\end{array}$ & $\begin{array}{c}\text { Maternal } \\
\text { Blood }\end{array}$ & $\begin{array}{c}\text { Cord } \\
\text { Blood }\end{array}$ & Liquor \\
\cline { 1 - 3 } & $20 \mathrm{~min}$ & 3.5 & 0.3 & $<0.1$ \\
7 & $20 \mathrm{~min}$ & 12.5 & 2.6 & 0.45 \\
9 & $54 \mathrm{~min}$ & 12.4 & 2.6 & $<0.1$ \\
15 & $1 \mathrm{hr}$ & 8.8 & 2.3 & 3.8 \\
40 & $2 \mathrm{hr}$ & 5.1 & 1.2 & 0.3 \\
59 & $41 \mathrm{hr}$ & $<0 \cdot 1$ & $<0.1$ & 0.32 \\
58 & $52 \mathrm{hr}$ & $<0.1$ & $<0.1$ & 0.17 \\
\hline
\end{tabular}

TABLE III-Maternal Blood, Cord Blood, and Liquor Levels of Lincomycin in $\mu \mathrm{g} / \mathrm{ml}$ obtained in Twin Pregnancies

\begin{tabular}{|c|c|c|c|c|c|}
\hline $\begin{array}{l}\text { Case } \\
\text { No. }\end{array}$ & Twin & $\begin{array}{c}\text { Time after } \\
\text { Injection }\end{array}$ & $\underset{\text { Blood }}{\text { Maternal }}$ & Cord & Liquor \\
\hline & 1 & $54 \mathrm{~min}$ & 12.4 & $2 \cdot 6$ & $<0.1$ \\
\hline 9 & $\begin{array}{l}2 \\
1\end{array}$ & $S_{2 \mathrm{hr} 40 \mathrm{~min}}^{56 \mathrm{~min}}$ & $\begin{array}{r}12 \cdot 4 \\
3 \cdot 2\end{array}$ & $2 \cdot 7$ & $\begin{array}{c}\text { No Spec. } \\
0.47\end{array}$ \\
\hline 52 & $\begin{array}{l}2 \\
1\end{array}$ & $\begin{array}{l}6 \mathrm{hr} 40 \mathrm{~min} \\
6 \mathrm{hr} 45 \mathrm{~min} \\
3 \mathrm{hr} 15 \mathrm{~min}\end{array}$ & $\begin{array}{l}2 \cdot 4 \\
2 \cdot 4 \\
7 \cdot 2\end{array}$ & $\begin{array}{l}0.8 \\
0.64 \\
-\end{array}$ & $\begin{array}{l}0 . \overline{94} \\
0.5\end{array}$ \\
\hline 12 & 2 & $\left\{\begin{array}{l}10 \mathrm{hr} 20 \mathrm{~min} \\
10 \mathrm{hr} 30 \mathrm{~min}\end{array}\right.$ & $\begin{array}{l}4 \cdot 2 \\
4 \cdot 2\end{array}$ & $\begin{array}{l}0.67 \\
0.89\end{array}$ & $3 \cdot 1$ \\
\hline
\end{tabular}

one hour after injection into the mother and in all cases where this interval exceeded six hours. In twin pregnancies almost identical levels of lincomycin were found in the cord bloods of each twin (table III) and were similar to levels found in single 
pregnancies. The liquor levels were less helpful as the specimens were obtained at different times, one being obtained at A.R.M. and the other at delivery.

\section{MULTIPLE DOSES}

Five patients received two doses, and one patient four doses, of lincomycin $600 \mathrm{mg}$ given at 12-hourly intervals before A.R.M. Maternal and cord blood samples were taken from all these patients, but liquor was obtained from only four. The levels were similar to those found after a single injection.

\section{NEONATAL DEATH}

One neonatal death occurred among the patients studied.

A 24-year-old Indian (case 40 , table II) had an elective caesarean section because of disproportion. A male infant weighing $3.2 \mathrm{~kg}$ was delivered with Apgar scores of 9 and 10. Four hours after delivery the baby developed signs of respiratory distress and subsequently showed clinical and radiological evidence of hyaline membrane disease. Neonatal death occurred on the third day. Post-mortem examination confirmed the diagnosis of hyaline membrane disease. Routine bacteriological swabs showed no evidence of any infection.

\section{TOXICITY}

One of the mothers delivered by caesarean section developed signs of neuromuscular block which persisted for four hours after delivery.

The patient, a 36-year-old Negro (case 9, tables II and III), had an emergency caesarean section at 37 weeks' gestation because of a shoulder presentation in the case of the first twin. Though in established labour for only three hours she had had intermittent uterine contractions for $\mathbf{3 0}$ hours before operation, and had received 16 doses of $15 \mathrm{ml}$ magnesium trisilicate at two-hourly intervals. The serum magnesium level at the time of operation was $3.0 \mathrm{mg} / 100 \mathrm{ml}$ (normal range $1 \cdot 6-2 \cdot 8$ ). Lincomycin had been given 54 minutes before operation and at operation the serum lincomycin level was $12.4 \mu \mathrm{g} / \mathrm{ml}$. Anaesthesia was induced with hyoscine $0.4 \mathrm{mg}$, thiopentone $250 \mathrm{mg}$, suxamethonium $75 \mathrm{mg}$, and pancuronium $6 \mathrm{mg}$, and maintained with nitrous oxide and oxygen. The operation was uneventful; the first twin weighed $2,500 \mathrm{~g}$ and had Apgar scores of 7 and 9; the second twin weighed 2,900 $\mathrm{g}$ and had Apgar scores of 7 and 10. The patient was given neostigmine $5.0 \mathrm{mg}$ and atropine $1.2 \mathrm{mg}$ to reverse the effect of the pancuronium, but postoperatively she developed hypoventilation, hypotension, and bradycardia with clinical signs of persistent neuromuscular block. These symptoms persisted for four hours after the operation before settling spontaneously.

\section{Discussion}

Several studies of the pharmacological behaviour of other antibiotics in late pregnancy have been reported. Speert (1943) found that sulphonamides rapidly appear in the fetal circulation, and Wolz and Wiley (1946) found the passage of penicillins into the liquor. Streptomycin, tetracycline, and chloramphenicol rapidly enter the fetal circulation, but only negligible levels of these antibiotics have been detected in the liquor (Charles, 1954; Sakula, 1954). Ampicillin behaves in a similar way to penicillin (Belcher et al., 1966; Williams and Felton, 1966). High levels of cephalosporins have been found in the liquor (MacAuley and Charles, 1968), though the fetal concentrations have shown some variation (Morrow et al., 1968; Paterson et al., 1970). Cephaloridine given by intramuscular injection behaves like ampicillin, with therapeutic concentrations entering both the liquor and the fetal circulation. In the case of cephalothin, while high liquor levels are found after intravenous administration, only negligible concentrations enter the fetal circulation (Stewart et al., 1973).

The present study confirms the blood levels obtained with lincomycin by Kaplan et al. (1965). Cord blood levels were about a quarter of the levels reached in maternal blood and showed elimination from the fetus in parallel to the mother. Lincomycin was not detecced in most cord bloods collected 24 hours after lincomycin had been injected into the mother.

The passage of lincomycin into and out of the liquor was more variable and slower, and demonstrable concentrations were still present 52 hours after a single injection. Repeated doses did not lead to any significant accumulation of lincomycin in any of the tissues; the liquor level of $5.2 \mu \mathrm{g} / \mathrm{ml}$ found two hours after four doses of lincomycin is only marginally higher than a level of $3.8 \mu \mathrm{g} / \mathrm{ml}$ found one hour after a single injection. The slower and more variable passage of lincomycin into the liquor probably reflects the role of fetal micturition in the formation of the liquor; lincomycin is rapidly excreted by the adult kidney and the variable concentrations found in the liquor may reflect varying rates of excretion in each fetus.

One of the seven patients delivered by caesarean section developed signs of persistent neuromuscular block which persisted for four hours after operation, despite having been given neostigmine at the end of the operation. Straw et al. (1965) produced a dose-related neuromuscular block in rabbits after intravenous injection of lincomycin in doses of 12.5, 25, and $50 \mathrm{mg} / \mathrm{kg}$. This block was not reversed an injection of neostigmine methylsulphate. They suggested that lincomycin could produce undesirable effects in the presence of other drugs which might enhance its neuromuscular blocking action. In the case described here, the slightly raised serum magnesium may have been a contributing factor as raised serum levels of magnesium may enhance neuromuscular block.

The administration of lincomycin caused no toxic reactions in any of the babies in this study. The one neonatal death was due to hyaline membrane disease after caesarean section and lincomycin could in no way be implicated.

Bacteroides are found as normal inhabitants of the mouth, colon, and urogenital tract. They have been isolated from cervical swabs of $6-18 \%$ of non-pregnant patients (Bollinger, 1964; Ansbacher et al., 1967), and are frequently isolated from patients who have postabortal infections (Carter, 1963; Pearson and Anderson, 1967, 1970), though these organisms were not isolated in any of the maternal deaths in England and Wales between 1967-9 (D.H.S.S., 1972). Bacteroides bacteraemia has also been reported in neonates (Robinow and Simonelli, 1965).

In-vitro tests have shown that lincomycin inhibits all isolates of the species Bacteroides fragilis with a minimum inhibitory concentration of $3.1 \mathrm{\mu g} / \mathrm{ml}$ (Kislak, 1972). Though only oneeighth as active as clindamycin, lincomycin can be given intramuscularly and is therefore more suitable for use during labour. This study shows that lincomycin passes the placental barrier in therapeutic concentrations and that there is no significant accumulation of lincomycin after repeated doses.

We thank Mr. W. W. McDougall, Mr. G. Mitchell, and Miss A. L. Reynolds for permission to study their patients. We also thank Dr. J. L. Shah for advice about the diagnosis and management of the patient with persistent neuromuscular block after caesarean section.

\section{References}

Ansbacher, R., Boyson, W. A., and Morris, J. A. (1967). American fournal of Obstetrics and Gynecology, 99, 394

Belcher, T. E., Edgar, W. M., Melville, H. A. H., and Peel, K. R. (1966). British Medical fournal, 1, 137.

Bollinger, C. C. (1964). Obstetrics and Gynecology, 23, 251

Carter, B. (1963). Proceedings of the Royal Society of Medicine, 56, 1095

Charles, D. (1954). Fournal of Obstetrics and Gynaecology of the British Commonwealth, 61, 750 . 
Department of Health and Social Security (1972). Report on Confidential Enquiries into Maternal Deaths in England and Wales, 1967-69, p. 86. London, H.M.S.O.

Geddes, A. M., Munro, J. F., Murdoch, J. McC., Begg, K. J., and Burns, B. A. (1967). In Proceedings of Fifth International Congress of ChemoB. A. (1967). In Proceedings of Fifth International Congress of Che

Gray, J. E., Purmalis, A., and Fienestra, E. S. (1964). Toxicology and Applied Pharmacology, 6, 476.

Kaplan, K., Chew, W. H., and Weinstein, L. (1965). American fournal of Medical Science, 250, 137.

Kislak, J. W. (1972). Fournal of Infectious Diseases, 125, 295. MacAuley, M. A., and Charles, D. (1968). American fournal of Obstetrics and

Medina, H., Fiske, N., Hjelt-Harvey, I., Brown, C. D., and Prigot, A. (1964). Antimicrobial Agents and Chemotherapy, 1963, 3, 189.

Morrow, S., Palmisano, P., and Cassidy, G. (1968). Fournal of Pediatrics, 73, 262.

O'Driscoll, K., Jackson, R. J. A., and Gallagher, J. T. (1969). British Medical fournal, 2, 477.

O'Driscoll, K., Jackson, R. J. A., and Gallagher, J. T. (1970). Fournal of Obstetrics and Gynaecology of the British Commonwealth, 77, 385.
Paterson, L., Henderson, A., Burnett, L. C., and McGurk, S. (1970). Fournal of Obstetrics and Gynaecology of the British Commontwealth, 77, 565.

Pearson, H. E., and Anderson, G. V. (1967). Obstetrics and Gynecology, 30,

Pearson, H. E., and Anderson, G. V. (1970). Obstetrics and Gynecology, 35,

Robinow, M., and Simonelli, F. A. (1965). American Fournal of Diseases of Children, 110, 92

Sakula, A. (1954). British fournal of Tuberculosis, 48, 69.

Speert, H. (1943). American fournal of Obstetrics and Gynecology, 45, 200

Stewart, K. S., Shafi, M., Andrews, J., and Williams, J. D. (1973). To be published.

Straw, R. N., Hook, J. B., Williamson, H. E., and Mitchell, C. L. (1965). Fournal of Pharmaceutical Sciences, 54, 1814.

Tracy, O., Gordon, A. M., Moran, F., Love, W. C., and McKenzie, P. (1972). British Medical fournal, 1, 280.

Williams, J. D., and Felton, D. J. C. (1966). Fournal of Obstetrics and Gynaecology of the British Commonwealth, 73, 654

Wolz, J. H. E., and Wiley, M. M. (1946). Fournal of the American Medical Association, 131, 969 .

\section{Hypertension in Renal Transplant Recipients: Role of Bilateral Nephrectomy}

Medical Unit, St. Mary's Hospital, London W.2

SIMON L. COHEN, M.B., M.R.C.P., Senior Medical Registrar (Present address: St. Mary's Hospital, Harrow Road, London W.9) recipients. Because of differing durations of follow-up the comparison was made at an arbitrary point six months after transplantation.

\section{Method}

The data for this study were collected by retrospective analysis of the follow-up charts of the kidney transplant recipients. At the six-month point after operation the patients returned to the clinic at monthly intervals, or more frequently if the kidney was functioning poorly. At least three sets of observations and frequently four or five were made for the period of five to seven months after operation. Means of the following parameters were recorded-systolic and diastolic blood pressure, serum creatinine, creatinine clearance, and prednisone dosage in $\mathrm{mg} / \mathrm{kg}$-and they were compared for the nephrectomized and nonnephrectomized patients. In addition the records were checked to see if the patients were receiving antihypertensive medication. In those noted to be hypertensive at six months the charts were analysed to determine the subsequent course of the blood pressure and renal function. For the purposes of this study hypertension was defined either as the presence of a sustained diastolic blood pressure of $100 \mathrm{~mm} \mathrm{Hg}$ or more or the requirement of antihypertensive drugs other than diuretics to control blood pressure.

The patients' records before transplantation were examined to see if they had malignant hypertension as defined by the presence of papilloedema and fundal haemorrhages and exudates, either before starting or during the dialysis period, and to find out if hypertension was a problem during the dialysis period. Details of any drugs required to control hypertension on dialysis were noted. Means of blood pressure recordings taken in the last month preceding transplantation were calculated.

The kidney transplants concerned in this study were performed between 1 January 1966 and 30 September 1971. In that time 147 kidneys were transplanted, of which 81 functioned for six months or more. These 81 are considered in this report. Fifty-nine transplants were grafted to bilaterally nephrectomized recipients and 22 were put into recipients who retained their own diseased kidneys. Only four of the kidneys were from live related donors, the remainder were cadaveric kidneys. 